\title{
The Dielectric Properties of Unfrozen Water in Carp Myofibrils under Frozen Conditions
}

\author{
Norio Inoue, Akihisa Kishimoto, Koji Yamazaki, \\ and Haruo Shinano \\ Faculty of Fisheries, Hokkaido University, Minato, Hakodate, Hokkaido 041, Japan \\ (Received September 18, 1995)
}

\begin{abstract}
The dielectric properties of carp myofibrils in the presence and absence of electrolytes under frozen conditions were measured. Unfrozen water was characterized by the apparent dielectric relaxation time $(\tau)$ and apparent activation energy calculated. The unfrozen water was divided into three groups that had different relaxation mechanisms by a Cole-Cole plot. The temperature-dependence (reciprocal of absolute temperature) of $\tau$ (Arrhenius plot) presented a biphasic pattern with a breaking point at -15.3 and $-23.2{ }^{\circ} \mathrm{C}$ in the absence and presence of electrolytes, respectively. In the temperature range from the breaking point to the lowest temperature examined, it seems that the unfrozen water is "unfreezable water" and corresponds to monolayer water. At the same time, it is considered that unfrozen water in the temperature range from the breaking point to the highest temperature examined corresponds to the bound water of multilayer water. The mobility of unfrozen and unfreezable waters increased in the presence of electrolytes under the temperatures examined.
\end{abstract}

Key words: myofibrils, dielectric relaxation time, water mobility, unfrozen water, bound water, activation energy

Nagashima and Suzuki showed that there were two types of unfrozen water by using a pulsed NMR, "unfrozen water" and "unfreezable water". ${ }^{1}$ "They also called them, "weak bound water" and "strong bound water", respectively, and stated that the two types of waters were separated at about $-20^{\circ} \mathrm{C}$. Water hydrated directly with proteins and saccharides corresponded to "strong bound water". When the water surrounding the proteins is in a stable state (restricted water of mobility), its reactivity is reduced. ${ }^{2)}$ It is known that the mobility of water molecules is reduced at lower temperatures and the relaxation time, which is one of the mobile indices of water, is longer under the same conditions. ${ }^{3)}$ Therefore, it is surmised that the reactivity (chemical reaction rates) of unfrozen water hydrated with proteins under conditions below the freezing point may be retarded by a temperature decrease. ${ }^{4)}$ Meanwhile, it is known that the mobility of hydrated water surrounding the dissociated ions from electrolytes is in the order of $10^{-12} \mathrm{sec}$, and that of surrounding proteins is in the order of $10^{-6} \mathrm{sec}^{2)}$ The hydrated water of the latter, therefore, is more stable than that of the former.

We investigated the hydration and mobility of unfrozen water, believing that the water mobility in fish meat during frozen storage may be related to freeze denaturation of muscle proteins. However, there have been few reports on the mobility of unfrozen water in muscle proteins and on the effect of electrolytes on the mobility under frozen conditions. ${ }^{\text {) }}$

The objective of this study was to assess the dielectric relaxation time $(\tau)$ of unfrozen water in carp myofibrils under the conditions below the freezing point, and to show the relationship between the $\tau$ and measuring temperatures and the effect of electrolytes on the $\tau$.

\section{Materials and Methods}

\section{Sample Preparation}

Carp myofibrils were prepared as described by Kitazawa et al. ${ }^{6}$ The final precipitation was centrifuged at $18,000 \times g$ for $15 \mathrm{~min}$, and used for the following measurements. Two samples in $20 \mathrm{~mm}$ phosphate buffer (pH 6.8) with and without $0.1 \mathrm{M} \mathrm{KCl}$ were prepared. Another two samples using $\mathrm{NaCl}$ were prepared using the same procedures.

\section{Dielectric Dispersion Measurements}

A device designed for the measurement of dielectric properties (Ando Electric Co. Ltd., TRS-10T type) was used..$^{7}$ The apparent dielectric constant $\left(\varepsilon^{\prime}\right)$ and apparent dielectric loss $\left(\varepsilon^{\prime \prime}\right)$ were measured over a frequency range of $30 \mathrm{~Hz}$ to $3 \mathrm{MHz}$. Suitable measuring temperatures were selected between -64 and $-4.5^{\circ} \mathrm{C}$. The acrylic cell for the equipment was set at a height of $5 \mathrm{~mm}$. The values of $\varepsilon^{\prime \prime}$ were plotted against frequency $(f)$, and apparent relaxation frequency $\left(f_{\mathrm{I}}, \mathrm{sec}^{-1}\right)$ was estimated from the maximum peak of the profile. The apparent dielectric relaxation time $(\tau, \mathrm{sec})$ was calculated using the following equation: $\tau=\left(2 \pi f_{\mathrm{r}}\right)^{-1}$.

\section{Water Content}

The total water content of the sample was determined by drying the samples in an air-oven at $105^{\circ} \mathrm{C}$ to a constant weight.

\section{Results and Discussion}

Dielectric Dispersion and Polarization

The $\varepsilon^{\prime}$-values of carp myofibrils without $\mathrm{KCl}$ (water con- 
tent, $87.3 \%$ ) decreased at higher frequencies (Fig. 1). Similar dielectric dispersions were recognized in another sample without $\mathrm{NaCl}$ (water content, 90.0\%) and two other samples with $\mathrm{KCl}$ (water content, 86.2\%) and $\mathrm{NaCl}$ (water content, $88.1 \%$ ) (data not shown). This phenomenon shows that the mobility of dipoles (of water molecules) at higher frequencies can not be synchronized with an alternating electric (dynamic) field. Comparing at the same frequency, the $\varepsilon^{\prime}$-value of the sample at lower temperatures was smaller (Fig. 1). Therefore, the $\varepsilon^{\prime}$-values at $100 \mathrm{kHz}$ for the samples including the other three samples described above were plotted as a function of measuring temperature (Fig. 2). The $\varepsilon^{\prime}$-value decreased as measuring temperature decreased. A marked decrease of $\varepsilon^{\prime}$-value (at 100 $\mathrm{kHz}$ ) of the samples without electrolytes $(\mathrm{KCl}$ and $\mathrm{NaCl})$, however, was observed from -4.5 to $-22^{\circ} \mathrm{C}$. This shows that the mobility of dipoles was restricted and could not be synchronized against the changes of alternating electric field at lower temperatures. The $\varepsilon^{\prime}$-values in the presence of electrolytes were larger than those in the absence of them at the same temperature in the range -50 to $-10^{\circ} \mathrm{C}$.

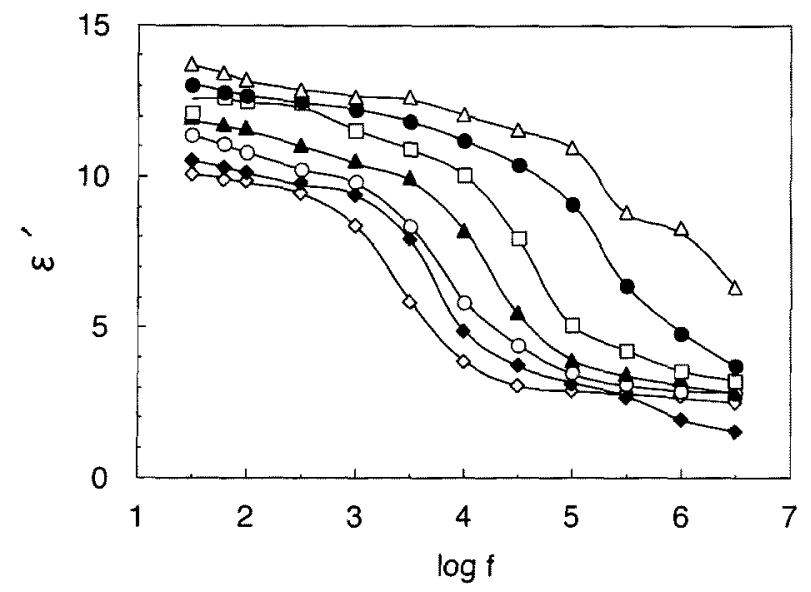

Fig. 1. Dielectric dispersion of carp myofibrils under frozen conditions. Water content (\%) was 87.3 .

Temperatures measured are at $-4.5(\triangle),-11.3(\bullet),-21.5(\mathrm{D})$, $-32.5(\Delta),-46.5(0),-52.5(\diamond)$, and $-63.5^{\circ} \mathrm{C}(\diamond)$.

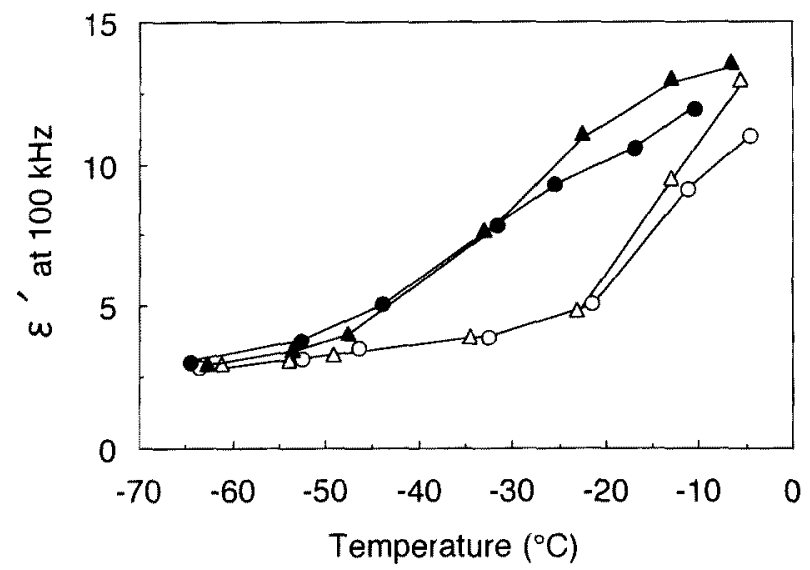

Fig. 2. The apparent dielectric constant $\left(\varepsilon^{\prime}\right)$ of carp myofibrils with and without electrolytes under frozen conditions at $100 \mathrm{kHz}$.

$\bigcirc$, without $\mathrm{KCl}$;, with $\mathrm{KCl}(0.1 \mathrm{M}) ; \Delta$, without $\mathrm{NaCl}$; and $\boldsymbol{\Delta}$, with $\mathrm{NaCl}(0.1 \mathrm{M})$.
This means that the polarization of water molecules was influenced by the addition of electrolytes. We reported a similar tendency at $25^{\circ} \mathrm{C}$ that the polarization of hydrated water in dehydrated kamaboko was influenced notably by the addition of $\mathrm{NaCl}$ in $9-20 \%$ moisture (wet basis) range. ${ }^{7}$

\section{$\varepsilon^{\prime} v s \varepsilon^{\prime \prime}$ (Cole-Cole plots)}

Three different circular arcs appeared in the Cole-Cole plots of the samples without electrolyte (water content, $87.3 \%$ ) at -21.5 and $-52.5^{\circ} \mathrm{C}$ (Fig. 3). It is suggested that there are three different groups of water mobility, and that none of them has a single relaxation mechanism, because none of the circular arcs is a well-defined semicircle. This means that the unfrozen water is affected by the other molecules present around the water molecule.

\section{$\tau$ vs Reciprocal of Absolute Temperature (I/T)}

It would seem that the mobility of water was restricted as the temperature decreased, because the $\tau$ values increased with decreasing temperature (Fig. 4). It is known that there is a linear relationship between $\log \tau$ and $1 / \mathrm{T}$ (Arrhenius plot). ${ }^{3)}$ Plots of $\tau$ (log scale) against reciprocal temperature behaved in a two-phase pattern with breaking points at $3.88 \times 10^{-3} \mathrm{~K}^{-1}\left(-15.3^{\circ} \mathrm{C}\right)$ without electrolytes and at $4.00 \times 10^{-3} \mathrm{~K}^{-1}\left(-23.2^{\circ} \mathrm{C}\right)$ with $\mathrm{KCl}$ and $\mathrm{NaCl}$ (Fig. 4). The values of $\tau$ in the temperature range from -4.5 to $-45^{\circ} \mathrm{C}$ without electrolytes and from -10.5 to $-60^{\circ} \mathrm{C}$ with $\mathrm{KCl}$ and $\mathrm{NaCl}$ were smaller than $22 \mu \mathrm{sec}$, which is the $\tau$ of ice at $0^{\circ} \mathrm{C} .^{8)}$ Hence, we thought that the values in Fig. 4 were based on the bound water which was in an unfrozen state and whose mobility had been reduced. In the temperature range from the breaking point to the highest temperature examined, $\tau$ values increased noticeably as the temperature decreased a few degrees (mobility of water molecules was decreased). This was thought to be due to crystalization of the water molecules which had a greater mobility. In the temperature range from the breaking point to the lowest temperature examined, the extent of changes of $\tau$ values with decreasing temperature was smaller than that of the temperature range described above. This seems to be mainly due to the presence of stable water molecules, because the water molecules may

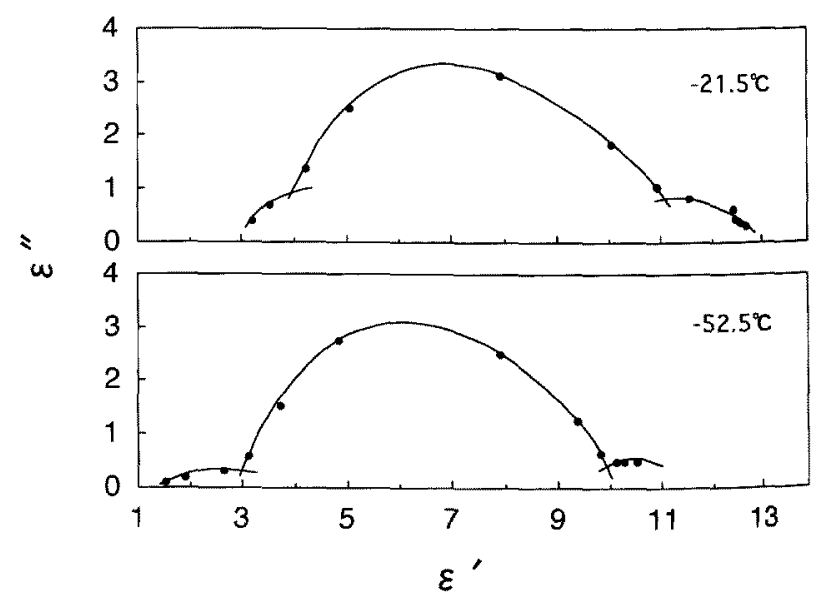

Fig. 3. Cole-Cole plots in low- and high-frequency dispersions of carp myofibrils without $\mathrm{KCl}$ at -21.5 and $-52.5^{\circ} \mathrm{C}$ Water content $(\%)$ was 87.3 . 


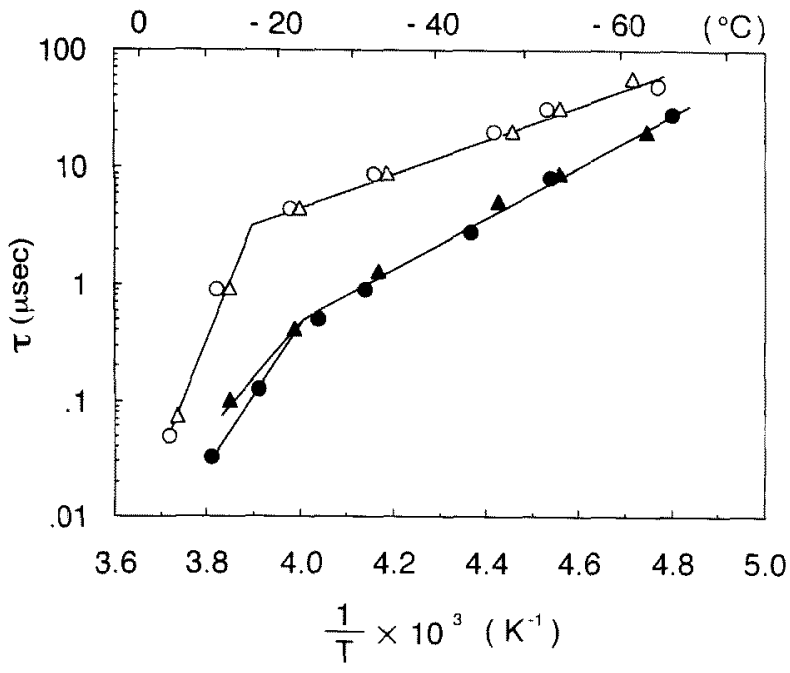

Fig, 4. The apparent relaxation times $(\tau)$ of carp myofibrils as a function of reciprocal of absolute temperature $(1000 / \mathrm{T})$. Symbols are the same as in Fig. 2.

have interacted with myofibrillar proteins and other constituents. Therefore, we thought that the waters in the temperature range which showed steep and gentle slopes corresponded to the "weak bound water (unfrozen water)" and "strong bound water (unfreezable water)" described by Nagashima and Suzuki," respectively.

Apparent activation energy (E) was estimated from the relationship shown in Fig. 4 (slope of a straight line). The $E$ values with and without electrolytes associated with the gentle slope were $42.57 \mathrm{~kJ} / \mathrm{mole}(10.17 \mathrm{kcal} / \mathrm{mole}, 1$ $\left.\mathrm{kcal}_{\mathrm{TT}}=4.1868 \mathrm{~kJ}\right)$ and $27.54 \mathrm{~kJ} / \mathrm{mole}(6.58 \mathrm{kcal} / \mathrm{mole})$, respectively. The $\mathrm{E}$ values associated with the steep slope were $219.70 \mathrm{~kJ} /$ mole $(52.49 \mathrm{kcal} / \mathrm{mole})$ without electrolytes, $113.26 \mathrm{~kJ} / \mathrm{mole}(27.06 \mathrm{kcal} / \mathrm{mole})$ with $\mathrm{KCl}$, and $86.51 \mathrm{~kJ} /$ mole $(20.67 \mathrm{kcal} /$ mole $)$ with $\mathrm{NaCl}$. The E values of the steep slope were larger than the $E$ value of pure ice, $55.46 \mathrm{~kJ} /$ mole $(13.25 \mathrm{kcal} /$ mole) $){ }^{3)}$ and those of the gentle slope were smaller than that of pure ice.

When a electric field is applied to ice and restricted unfrozen water, the dipoles may become oriented to the electric field by overcoming the interactions with proteins and other constituents surrounding the water molecules. The energy per 1 mole of ice and water to achieve such an orientation is $\mathrm{E}$. The unfreezable water in the lower temperature range with gentle slope with and without electrolytes was oriented at a smaller E value (maybe one or two hydrogen bonds) than that of pure ice. Since the unfreezable water in this temperature range must hydrate with proteins by hydrogen bonding, it is suggested that only one layer of water adjacent to the protein surface participates for this binding energy. We considered that this "unfreezable water" corresponded to the monolayer water. ${ }^{\text {") }}$

In the higher temperature range with steep slope, the amount of unfrozen water which has a greater mobility may have increased. ${ }^{10}$ ) The binding energies of unfrozen water are counterbalanced in small crevices or pores, because water confined in small space interacts with monolayer water forming a three-dimensional network. Consequently, the $E$ value of the unfrozen water is much larger than that of the unfreezable water, because the water must be oriented by overcoming the counterbalanced binding energies. We therefore concluded that the "unfrozen water" corresponded to the bound water of multilayer water. ${ }^{11}$ No clear explanation for the hydration of unfrozen water has been formulated. ${ }^{12)}$ The results of this study could provide valuable information on the hydration of unfrozen and unfreezable waters under frozen conditions.

\section{Influence of Electrolytes on Unfrozen Water}

The mobility of unfrozen and unfreezable waters increased in the presence of electrolytes under the temperature range examined (Fig. 4). In the temperature range -50 to $-10^{\circ} \mathrm{C}$, the polarization of these water molecules was affected by the presence of electrolytes (Fig. 2). This means that these waters are affected by electrolytes, even if the examined temperature is below the eutectic point of the electrolyte, $\mathrm{KCl}$ or $\mathrm{NaCl}$.

Since the $E$ value with electrolyte was smaller than that without electrolyte in the temperature range with steep slope (Fig. 4), the counterbalanced binding energies could be weakened in the presence of electrolyte. In the temperature range with gentle slope, the $E$ value with electrolyte was greater than that without electrolyte. This could be explained by assuming that the water molecules of monolayer water were oriented around the ions of the electrolyte by the attractive force between the water molecule and the ion.

\section{References}

1) N. Nagashima and E. Suzuki: A method for continuous determination of unfrozen water, in "Superchilling (Subzero Temperature) Storage of Fish" (ed. by T. T. Kozima), Koseisha Koseikaku, Tokyo, 1986, pp. 39-49 (in Japanese).

2) H. Uedaira: Water for Life. Kyoritsu Shuppan, Tokyo, 1990, 96p. (in Japanese).

3) R. P. Auty and R. H. Cole: Dielectric properties of ice and solid $\mathrm{D}_{2}$ O. J. Chem. Phys., 20, 1309-1314 (1952).

4) M. S. Brown: Frozen fruits and vegetables, Their chemistry, physics, and cryobiology. Adv. Food Res., 25, 181-235 (1979).

5) Y. Nozaki: The denaturation of fish muscle protein and present state of water. Doctoral thesis, Hokkaido University, Sapporo, Hakodate, 1987, 198p. (in Japanese).

6) H. Kitazawa, Y. Kawai, N. Inoue, and H. Shinano: Influence of $\mathrm{KCl}$ on the decrease of $\mathrm{Ca}^{2+}$-ATPase activity and solubility of carp myofibrils during frozen storage (Short paper). Fisheries Sci., 61, 1037-1038 (1995).

7) N. Inoue, R. Hamahata, Y. Minegishi, and H. Shinano: The dielectric properties and mobility of hydrated water in dehydrated kamaboko. Nippon Suisan Gakkaishi, 59, 1381-1388 (1993).

8) O. Fennema: Water and ice, in "Low-Temperature Preservation of Food and Living Matter" (ed. by O. Fennema, W. D. Powrie, and E. H. Marth), Ist ed., Marcel Dekker Inc., New York, 1973, pp. 377.

9) M. Schnepf: Protein-water ineractions, in "Water and Food Quality" (ed. by T. M. Hardman), Elsevier Science Publishers, London and New York, 1989, pp. 135-167.

10) K. Takahashi, N. Inoue, and $H$. Shinano: Effect of storage temperature on freeze denaturation of carp myofibrils with $\mathrm{KCl}$ or $\mathrm{NaCl}$. Nippon Suisan Gakkaishi, 59, 519-527 (1993).

11) O. Fennema: Water and protein hydration, in "Food Proteins" (ed. by J. R. Whitaker and S. R. Tannenbaum), AVI Publishing Co., Westport, Connecticut, 1977, pp. 50-90.

12) I. D. Kuntz and W. Kauzmann: Hydration of proteins and polypeptides. Adv. Protein Chem., 28, 239-245 (1974). 